\title{
La Enseñanza Secundaria brasileña y la cuestión de la dualidad escolar
}

\author{
Caroline de Lima Mendonça \\ carol.lima.mendonca@ hotmail.com \\ https://orcid.org/0000-0002-3326-4649 \\ Universidade Estadual do Paraná (UNESPAR)- Campus Paranavaí \\ Paranavaí, Brasil. \\ Neide de Almeida Lança Galvão Favaro \\ neidegafa@hotmail.com \\ https://orcid.org/0000-0003-0569-7225 \\ Universidade Estadual do Paraná (UNESPAR)- Campus Paranavaí \\ Paranavaí, Brasil. \\ Priscila Semzezem \\ priscilasemzezem@ hotmail.com \\ https://orcid.org/0000-0002-5410-2585 \\ Universidade Estadual do Paraná (UNESPAR)- Campus Paranavaí \\ Paranavaí, Brasil. \\ Rita de Cássia Pizoli \\ ritacpizoli@hotmail.com \\ https://orcid.org/0000-0003-0127-3679 \\ Universidade Estadual do Paraná (UNESPAR)- Campus Paranavaí \\ Paranavaí, Brasil.
}

Recibido: 13/11/2020 Aceptado: 03/05/2021

\section{Resumen}

Las reformas educativas brasileñas emprendidas desde la década de 1990, y la más reciente Reforma de la Enseñanza Secundaria, de 2017, requieren análisis críticos que puedan contribuir para aclarar intenciones imbuidas en ese proceso. Tales intenciones no son visibles en su apariencia, y demandan estudios sobre las relaciones sociales capitalistas. Entre las cuestiones educativas que se despegan hoy en día, la dualidad de la Enseñanza Secundaria ha sido un tema que aparece en varias investigaciones en el ámbito de la perspectiva crítica. En ese sentido, este estudio tiene el objetivo de analizar la cuestión de la dualidad en la Enseñanza Secundaria brasileña y en sus políticas educativas, comprendiendo el período de la década de 1990 adelante, considerando su vinculación con la sociabilidad del capital. Se trata de una investigación bibliográfica y cualitativa, anclada en marco teórico-metodológico del materialismo histórico. En síntesis, el estudio demostró que la dualidad escolar solamente tiene sentido se dirigida para la desigualdad social estructurante en las relaciones capitalistas, reflejada en las reformas educativas y en la Enseñanza Secundaria, pues que es producto de la organización social que tiene como matriz la propiedad privada.

Palabras clave: Capitalismo. Dualidad Escolar. Enseñanza Secundaria. 


\title{
O Ensino Médio brasileiro e a questão da dualidade escolar
}

\begin{abstract}
Resumo
As reformas educacionais brasileiras, empreendidas desde a década de 1990, e a mais recente Reforma do Ensino Médio, de 2017, requerem análises críticas que possam contribuir para o desvelamento das intenções imbuídas nesse processo. Tais intenções não são visíveis em sua aparência, e demandam, em consonância, estudos sobre as relações sociais capitalistas. Entre as questões educacionais que se destacam na atualidade, a dualidade do Ensino Médio tem sido um tema que aparece em várias pesquisas no âmbito da perspectiva crítica. Nesse sentido, este estudo objetiva analisar a questão da dualidade no Ensino Médio brasileiro e em suas políticas educacionais, abarcando o período da década de 1990 em diante, considerando sua vinculação à sociabilidade do capital. Trata-se de uma pesquisa bibliográfica e qualitativa, amparada no referencial teórico-metodológico do materialismo histórico. Em síntese, o estudo demonstrou que a dualidade escolar só tem sentido se remetida à desigualdade social estruturante nas relações capitalistas, refletida nas reformas educacionais e no Ensino Médio, pois é produto da organização social que tem como matriz a propriedade privada.
\end{abstract}

Palavras-chave: Capitalismo. Dualidade Escolar. Ensino Médio.

\section{Brazilian High School and the school duality issue}

\begin{abstract}
Brazilian educational reforms performed from the 1990s and the latest High School Reform, in 2017, require critical analysis to contribute with unveiling the intentions imbued in this process. Such intentions are not visible in their appearance, and demand studies on the capitalist social relations. Among the educational issues that stand out today, duality in High School has been a theme that occurs in numerous researches in the critical perspective scope. Therefore, this study has as aim at analyzing the duality issue in Brazilian high school and in its educational policies, comprehending from the 1990s onwards, considering their linking to the capital sociability. This is a bibliographic and qualitative research based on the theoretical-methodological framework of historical materialism. In summary, the study demonstrated that school duality only makes sense whether addressed to the structuring social inequality in capitalist relations reflected in educational reforms and in High School, because it is a product by social organization which has as matrix the private property.
\end{abstract}

Keywords: Capitalism. School Duality. High School.

\section{Introdução}

A compreensão da educação a partir de aspectos pedagógicos e políticos é insuficiente, pois ela é parte integrante da ampla totalidade social. No caso das políticas educacionais brasileiras, elas estão em consonância com as demandas do capital mundializado e atendem a um objetivo bem definido, de servir aos seus interesses de acumulação. Tendo em vista os complexos elementos estruturais que permeiam a sociabilidade do capital, captar esse processo 
em seu movimento não é tarefa simples, mas um desafio necessário a ser enfrentado para assegurar a leitura mais aproximada da realidade social e educacional.

A fim de viabilizar a discussão, optou-se por delimitar este estudo no Ensino Médio, considerando a questão da dualidade que vem permeando suas análises mais críticas. A legislação brasileira, bem como os documentos oficiais e as políticas educacionais referentes ao Ensino Médio, definem propostas que o apresentam como uma unidade, porém, historicamente, houve uma desigualdade de condições de escolarização, especialmente neste nível de ensino, que se restringia a poucos e, para quem o alcançava, significava o fim do percurso formativo institucionalizado. Na concreticidade real, este nível de ensino, que constitui a etapa final da Educação Básica desde 1996, tem sido alvo de várias reformas políticas e de acirradas disputas. Recentemente, o Ensino Médio sofreu nova alteração com a Lei n ${ }^{\circ} 13.415 / 2017$, o que desencadeou profundas polêmicas.

Nesse cenário, grande parte das pesquisas educacionais baseadas em uma perspectiva crítica sustentam a tese da "dualidade" que permeia o Ensino Médio (Kuenzer, 2007; Ciavatta; Ramos, 2011). Em linhas gerais, interpretam que as "elites" obtém uma formação que lhes permite prosseguir no desenvolvimento intelectual, com oportunidades de acesso ao ensino superior, enquanto que as classes trabalhadoras ficam restritas à formação para o trabalho, que se dá nos cursos profissionalizantes e técnicos no Ensino Médio. Na defesa dos interesses dos trabalhadores, advogam a necessidade de assegurar a igualdade de condições educacionais para todos.

Neste artigo objetiva-se analisar a questão da dualidade que vem sendo constatada nas funções do Ensino Médio brasileiro e em suas políticas educacionais, abarcando o período da década de 1990 em diante, considerando sua vinculação à sociabilidade do capital.

Trata-se de uma pesquisa bibliográfica e documental de abordagem qualitativa, tendo como referencial teórico-metodológico o materialismo histórico. Sua base são autores clássicos e contemporâneos e, ainda, documentos oficiais. Articulam-se as questões educacionais com a totalidade social, considerando seus aspectos socioeconômicos, a fim de assegurar a abordagem da questão em seus fundamentos.

$\mathrm{Na}$ exposição dos resultados obtidos, inicia-se com a análise das políticas educacionais que afetaram o Ensino Médio no Brasil, desde a Lei n 9.394/1996, a Lei de Diretrizes e Bases da Educação Nacional (LDBEN), até a atual Reforma do Ensino Médio, consubstanciada na Lei 
$n^{\circ}$ 13.415/2017. As funções que vêm sendo atribuídas a esse ensino são desveladas, apreendendo-se os fundamentos das reformas legais, articulados ao movimento de reprodução capitalista e, consequentemente, às suas demandas em relação aos trabalhadores. Por fim, analisam-se elementos que perpassam as discussões sobre a “dualidade” do Ensino Médio, tendo em vista sua vinculação à lógica do capital.

\section{O Ensino Médio a partir dos anos de 1990: Reformas e interesses do capital}

A significativa quantidade de normativas que marcou esse nível de ensino desde a década de 1990 evidencia a importância do Ensino Médio e o frequente embate de interesses que permeia sua regulamentação. Analisar esse processo para além de seus efeitos requer vinculálo à totalidade social. Ressalta-se que o campo das políticas e da educação é demarcado por tensões diversas, cuja origem assenta-se em elementos econômicos e sociais.

Estes, por sua vez, têm raízes históricas e inserem-se no âmbito de determinada relação de produção da vida humana. Na atualidade, ela se reproduz mediada pela relação social do capital, que foi desvelada em suas origens e em sua lógica interna incontrolável, desde o século XIX:

A sociedade burguesa com as suas relações de produção e de troca, o regime burguês de propriedade, a sociedade burguesa moderna, que conjurou gigantescos meios de produção e de troca, assemelha-se ao feiticeiro que já não pode controlar os poderes infernais que invocou. Há dezenas de anos, a história da indústria e do comércio não é senão a história da revolta das forças produtivas modernas contra as modernas relações de produção, contra as relações de propriedade que condicionam a existência da burguesia e seu domínio (Marx \& Engels, 2005, p. 48).

Com o estabelecimento do modo de produção capitalista a produção humana passou a ser realizada por meio do mercado, que para L. Tumolo e P. Tumolo (2019, p. 134) pode ser entendido "[...] como o lugar social no qual todos os indivíduos, para poderem viver, precisam comprar e vender mercadorias". Cabe salientar que, por mercadoria, entende-se tudo aquilo que satisfaz necessidades humanas, não se referindo apenas a objetos. Sob o capital, a força de trabalho é uma mercadoria.

Nessa forma de organização social, existem duas classes essenciais: os proprietários dos meios de produção (burguesia) e os não proprietários dos meios de produção (proletariado). L. Tumulo e P. Tumolo (2019) atentam-se ao fato de que os proprietários dos meios de produção podem estabelecer duas relações: capitalistas (quando há compra de força de trabalho) e não 
capitalistas (aquele que produz para a própria subsistência e para valor de troca). Desse modo, capitalistas são aqueles que detém os meios de produção e compram força de trabalho. Já a outra classe social, dos não proprietários dos meios de produção, é constituída por aqueles que vendem a única mercadoria de que dispõem, a sua força de trabalho, demarcando a sua condição de trabalhadores.

É no interior dessa lógica societal que radicam os distintos interesses em relação ao Ensino Médio, pois suas funções acabam sendo definidas, em última instância, pelas demandas da lógica do capital, cujo objetivo é a sua reprodução ampliada. Com esta afirmação não se desconsideram as lutas contraditórias que se dão nesse processo e sua importância, mas trata-se de revelar suas determinações fundamentais.

O processo de transformações que marcou o Ensino Médio brasileiro nas últimas décadas esteve associado às necessidades do capital e só a partir delas é possível compreender as funções que ele assumiu. A partir da década de 1980, a relação entre os distintos países e o Banco Mundial (BM) se alterou, devido à crise e à vulnerabilidade dos países endividados. Essa entidade econômica impôs novas condicionalidades para a concessão de empréstimos, assegurando uma intervenção direta nas formulações de políticas internas, influenciando a legislação desses países, que acabaram aderindo ao neoliberalismo (Soares, 2000).

A “virada neoliberal" foi efetivada deste modo, a partir de pressões econômicas e de uma forte propagação ideológica que circulou em toda sociedade civil (universidades, igrejas, escolas, associações profissionais). Buscou-se por essa via o consentimento das classes populares, a fim de converter o modo de pensar, legitimando a ideia de garantia e exclusividade de liberdade ao neoliberalismo (Harvey, 2008).

O capital, ao veicular tal ideário, obtém a redução das funções estatais ligadas aos direitos sociais, tendo em vista a necessidade de subsunção da vida social à lógica mercantil. Ao contrário do que se difunde, não ocorre a diminuição do Estado no todo, afinal, a economia capitalista não funciona sem a sua intervenção. Por isso, ao afirmar a necessidade dessa forma de Estado, os monopólios e seus representantes procuram, na verdade, “[...] um Estado mínimo para o trabalho e máximo para o capital” (Netto \& Braz, 2006, p. 227).

No Brasil, foi no governo de Fernando Henrique Cardoso (FHC), que abarcou o período de 1995 a 2002, que se aprofundou a implementação de políticas neoliberais no país, com as 
privatizações de estatais, terceirizações de serviços do Estado, abertura do mercado nacional para empresas estrangeiras, flexibilização das relações de trabalho, dentre outras medidas.

Nessa conjuntura, os protagonistas da educação brasileira vivenciam disputas acirradas desde a década de 1990, que envolvem o Ensino Médio. O projeto da atual LDBEN, formulado no período de "redemocratização" por mais de 30 organizações científicas, políticas e sindicais, congregadas no Fórum Nacional em Defesa da Escola Pública, foi recusado sob a estratégia da proposição de várias emendas e de um “infindável” processo de tramitação, abrindo brechas para a implantação de uma reforma educacional por meio de Decretos (Frigotto \& Ciavatta, 2003).

Como resultado, o projeto da LDBEN oriundo das organizações dos educadores foi coordenado, negociado e desfigurado pelos relatores do bloco de sustentação governamental. "Tratava-se de uma estratégia para, ao mesmo tempo, ir transformando esse substitutivo em projeto adequado aos interesses do governo e ir impondo sua política de ajuste pontual e tópico no campo educacional" (Frigotto \& Ciavatta, 2003, p. 110).

Como produto desse processo, aprovou-se a LDBEN, Lei $\mathrm{n}^{\circ}$ 9.394, em 20 de dezembro de 1996, no período marcado pelos dois mandatos de FHC na Presidência. Ela reafirmou o direito à educação, desde a Educação Básica até o Ensino Superior, embora os atos de sua regulamentação tenham sido compatíveis com o "Estado Mínimo" e os anseios de desregulamentação, descentralização e privatização.

O Ensino Médio, foco de discussão desta pesquisa, deixa de se configurar na LDBEN de 1996 como etapa intermediária entre o Ensino Superior ou o mercado de trabalho, e passa a ter caráter formativo e de conclusão da Educação Básica. Segundo Zibas (2005), os ensinos fundamental e médio deveriam estabelecer uma sequência educacional integrada a partir desta Lei, o que pode ser considerado um avanço. Importante demarcar que, ao considerar o Ensino Médio como Educação Básica, ele passou a ser direito de todo cidadão brasileiro.

O Art. 22 da LDBEN estabeleceu como objetivo da Educação Básica “[...] desenvolver o educando, assegurar-lhe a formação comum indispensável para o exercício da cidadania e fornecer-lhe meios para progredir no trabalho e em estudos posteriores" (Brasil, 1996). O Ensino Médio, enquanto etapa conclusiva da Educação Básica, passou a ter como função a continuidade e o aprofundamento dos conhecimentos científico-tecnológicos, bem como a formação ética, o desenvolvimento intelectual crítico e a preparação para o trabalho. 
Destaca-se que a LDBEN já propugnou a "flexibilidade a novas condições" como uma de suas funções. Para atingir tais fins, o Ensino Médio teria uma carga horaria mínima anual de oitocentas horas, com duração de três anos, totalizando 2.400 horas, no mínimo.

Quanto ao currículo, a atual LDBEN determinou que todos os níveis de ensino deviam seguir uma base nacional comum. No Art. 26, parágrafo $1^{\circ}$, dispôs que: “Os currículos a que se refere o caput devem abranger, obrigatoriamente, o estudo da língua portuguesa e da matemática, o conhecimento do mundo físico e natural e da realidade social e política, especialmente do Brasil” (Brasil, 1996). Estabeleceu a inclusão da filosofia e da sociologia, bem como das ciências humanas e da natureza, da língua portuguesa e da matemática, além da arte, como disciplinas obrigatórias em todas as séries do Ensino Médio.

Para Borges e Araújo (2019), a LDBEN de 1996 promoveu uma nova estruturação da educação no Brasil, organizada em Educação Infantil, Ensino Fundamental, Ensino Médio e Ensino Superior. Ela acabou permitindo, entretanto, a separação do sistema de ensino regular e do sistema de Educação Profissional (nível básico, técnico e tecnológico).

Os ajustes econômicos propagados como necessários foram adotados nas políticas brasileiras e, consequentemente, também no Ministério da Educação (MEC), que difundiu um pensamento pedagógico empresarial, em consonância com as diretrizes das entidades internacionais econômicas. A aprovação da LDBEN deu-se nesse contexto, o que explica a rejeição às demandas mais progressistas em sua redação final.

No que se refere ao objeto deste estudo, o Decreto $n^{\circ} 2.208 / 1997$ foi uma das medidas polêmicas do período, tendo em vista a separação que promoveu entre o Ensino Médio e o Profissional, contradizendo os defensores de uma educação igualitária para todos.

Nessa lógica, o Decreto ${ }^{\circ}$ 2.208, aprovado em 17 de abril de 1997, foi uma legislação complementar à LDBEN de 1996. Ele determinou a dissociação entre o Ensino Médio e o Ensino Profissional, o que ocasionou sistemas e redes distintas, “[...] além de se contrapor à perspectiva de uma especialização profissional como etapa que ocorreria após a conclusão de uma escola básica unitária” (Borges \& Araújo, 2019, p. 21).

É possível afirmar que a LDBEN de 1996, juntamente com o Decreto n 2.208/1997, “[...] que regulamenta o $\S 2^{\circ}$ do art. 36 e os artigos 39, 40, 41 e 42 da Lei $n^{\circ} 9.394$, de 20 de dezembro de 1996, instituíram as bases para a reforma do ensino profissionalizante" (Borges \& 
Araújo, 2019, p. 21). As instituições públicas e privadas de educação profissional alinharam-se assim às diretrizes estabelecidas nessa legislação.

No âmbito das contradições sociais, verificou-se nesse momento uma efetiva ampliação de matrículas na Educação Básica. Para além dos dados quantitativos, porém, é preciso analisar isso considerando a variação de seus efeitos em distintos contextos e o fato de que o Ensino Médio não se universalizou. Ademais, esse aumento nas matrículas revelou "[...] novos mecanismos de hierarquização e novas formas de exclusão diluídas ao longo do processo de escolarização e da vida social” (Altimann, 2002, p. 77).

A conjuntura política brasileira ganhou contornos diferenciados com os governos do Partido dos Trabalhadores (PT), desde os dois mandatos de Luiz Inácio Lula da Silva (20032010) até as gestões e o impeachment de Dilma Rousseff (2011-2016). No que se refere ao Ensino Médio, diante de várias resistências e críticas ao Decreto $n^{\circ}$ 2.208/1997, houve sua substituição pelo Decreto $\mathrm{n}^{\circ}$ 5.154, em 23 de julho de 2004. Foi restabelecida então a possibilidade de oferta do Ensino Técnico e Médio, de forma integrada, entretanto, sem excluir as alternativas de separação entre estas duas modalidades de ensino, permitindo a manutenção da situação vigente desde o Decreto n ${ }^{\circ}$ 2.208/1997.

Para Leher (2005, p. 51): “Analisando as medidas implementadas até o momento é possível constatar que as políticas dos organismos internacionais seguem guiando os cérebros do governo Lula da Silva”. Na prática, legitimou-se uma formação desvinculada, que favoreceu empresários e direção de escolas técnicas, impulsionando sua mercantilização.

Ademais, Santos (2017, p. 171) afirma que, ao se tratar da integração entre Ensino Médio e Profissional, deve-se levar em consideração que isso requer pelo menos boas estruturas, escolas equipadas e professores preparados para atuar. Mediante a realidade das escolas e dos estudantes do país, nota-se a impossibilidade dos cursos em dois turnos, para proporcionar uma formação comum e profissional de modo adequado, o que dá espaço para financiamentos privados. Assim, a "[...] dicotomia entre formação propedêutica e profissionalizante não é superada pela legislação vigente" (Santos, 2017, p. 171).

Além disso, em meio a esse processo, de acordo com Neves e Pronko (2008, p. 13), o projeto neoliberal nesse momento ganhou "[...] um elemento mais letal: o estilhaçamento do frágil campo de esquerda e a anulação de um acúmulo de mais de um quarto de século de luta por mudanças estruturais e de horizontes socialistas". 
Com a posse de Michel Temer (2016-2019), que ocorreu em um ambiente de dúvidas quanto à legalidade e legitimidade do impeachment de Dilma Rousseff, foi imposta com rapidez a Medida Provisória (MP) n 746/2016, que reformou o Ensino Médio, em meio a resistências e protestos de diversos segmentos sociais. Medida essa que se deu de forma autoritária e que foi, segundo Ferretti (2018, p.17), a etapa semifinal de todo um processo que se iniciou no ano de 2013, com o Projeto de Lei $n^{\circ}$ 6840/2013, “[...] apresentado por uma Comissão Especial da Comissão de Educação da Câmara dos Deputados".

A Lei n $n^{\circ} 13.415$, de 16 de fevereiro de 2017, consolidou a Reforma do Ensino Médio, também denominada por seus críticos de "contrarreforma". Ela trouxe significavas alterações normativas, incluindo dispositivos da LDBEN de 1996; da Lei $\mathrm{n}^{\circ}$ 1.494/07, que regulamenta o Fundo de Manutenção e Desenvolvimento da Educação Básica e de Valorização dos Profissionais da Educação (Fundeb); da Consolidação das Leis do Trabalho (CLT); dentre outras legislações (Brasil, 2017).

Diante das resistências e para obter o consentimento social, seus idealizadores usaram como argumento o fato desse nível de ensino não ter atingido nas últimas avaliações dos Índices de Desenvolvimento da Educação Básica (IDEB) números satisfatórios e, por isso, a "necessidade" de modificação dos currículos, segundo Costa e Coutinho (2018). Além disso acenaram com a "liberdade" que a mesma traria aos jovens, para decidirem seus caminhos formativos.

O currículo do Ensino Médio passou assim a ser orientado por uma Base Nacional Comum Curricular (BNCC) e por cinco itinerários formativos, o que alterou profundamente o Art. 36 da LDBEN de 1996. Este passou a vigorar com a seguinte redação:

Art. 36. O currículo do ensino médio será composto pela Base Nacional Comum Curricular e por itinerários formativos, que deverão ser organizados por meio da oferta de diferentes arranjos curriculares, conforme a relevância para o contexto local e a possibilidade dos sistemas de ensino, a saber:

I - linguagens e suas tecnologias;

II - matemática e suas tecnologias;

III - ciências da natureza e suas tecnologias;

IV - ciências humanas e sociais aplicadas;

V - formação técnica e profissional (Brasil, 2017).

Institui-se a proclamada "flexibilização" desse ensino, que foi além das questões curriculares, afetando também suas formas de integralização e o financiamento do ensino público. Isto se deu com a inclusão da educação a distância (Ead) como opção para cumprir 
parte da carga horária do Ensino Médio e com o fomento das parcerias público-privadas (PPP). Essas alterações foram substantivas e precisam ser compreendidas a fundo.

Há concordância quanto aos insatisfatórios resultados de aprendizagem, no entanto, ao adotar-se como solução as mudanças curriculares, não é assegurada melhoria na Educação Básica. Seus problemas não se resumem a currículos supostamente defasados, mas estão radicados em questões de ordem estrutural. Há aspectos cruciais desconsiderados e que dependem das prioridades sociais adotadas. Dentre eles, destacam-se a falta de investimentos, de estrutura adequada e de melhores condições de trabalho dos professores, que repercutem diretamente na qualidade do ensino e do aprendizado.

Para Costa e Coutinho (2018, p. 1642), não há possibilidade de desenvolver melhores “[...] índices educacionais sem elaborar políticas de investimentos em planos de carreira dos profissionais da educação, em infraestrutura física e humana das instituições de ensino”. A suposta melhoria do Ensino Médio, portanto, cai por terra se isso não é levado em conta.

Na aplicação prática da Reforma do Ensino Médio, a organização das áreas “[...] e das respectivas competências e habilidades será feita de acordo com critérios estabelecidos em cada sistema de ensino" (Brasil, 2017). Isso significa que os currículos, compostos por disciplinas obrigatórias (língua portuguesa e matemática) e não obrigatórias (educação física, artes, filosofia, arte, sociologia), serão ofertados de acordo com as condições materiais de cada escola. Por conseguinte, torna-se evidente a ilusão da suposta liberdade proclamada aos estudantes, que na prática é concretizada, ao menos para aqueles que dependem do ensino público, como uma liberdade restrita às opções e condições de cada localidade particular.

Observa-se que, sob a batuta de governos conservadores, se consuma desde 2016 a imposição arbitrária e veloz de normativas para a educação e para o Ensino Médio que, ignorando as discussões da área educacional, atendem diretamente aos imperativos da lógica do capital, viabilizando a gradual privatização da educação pública em geral e promovendo, desde a Lei no 13.415/2017, a mercantilização do Ensino Médio.

A partir do processo de reformas veiculados desde a década de 1990, portanto, ganhou força e se consumou uma educação "flexibilizada", pautada em objetivos assentados nas competências e habilidades, em uma perspectiva alinhada às necessidades de formação das classes trabalhadoras para o capital. Tendo em vista a relação social incontrolável e desigual, típica do capital, que não assegura empregos para todos e é marcada por crises inevitáveis e 
eminentes, a educação adquire uma função importante também para a conformação social. A "dualidade" do Ensino Médio precisa ser entendida no âmbito dessa realidade. Isto requer ir além da discussão das alterações políticas no Ensino Médio, avançando para a identificação de suas causas.

\section{Dualidade educacional: Algumas reflexões críticas}

A comunidade educacional científica tem se debruçado com afinco na crítica às políticas consideradas prejudiciais à educação da classe trabalhadora, propondo uma educação integral e igualitária para todos, denunciando os limites das reformas destinadas ao Ensino Médio. Um dos argumentos interpretativos centrais utilizados é o da "dualidade" que perpassa as propostas vigentes.

Esse debate teve influência da Sociologia Francesa, que teceu críticas à escola capitalista desde a década de 1960. Favaro (2017) analisa a obra L'école capitaliste em France (1971), de Roger Establet e Christian Baudelot, problematizando o rótulo que receberam no Brasil, de “crítico-reprodutivistas". Os autores asseguraram haver na França dos anos de 1960 uma divisão do aparelho escolar em duas redes de escolarização. A primeira era a rede primária profissional (PP), com cursos técnicos profissionalizantes focados na preparação para o trabalho; e a segunda a rede secundária superior (SS), que dava acesso a estudos universitários e à preparação para o trabalho intelectual. Na acepção dos teóricos franceses, a orientação para a rede PP ou SS era expressão das contradições sociais, que determinavam a oferta escolar.

\footnotetext{
Disso não se deduz que a escola fosse o instrumento e a causa da divisão da sociedade em classes, pois os autores deixaram claro que as classes sociais preexistem à escola. O que ocorria na escola, a separação dos indivíduos para as duas redes, só era possível porque as duas redes existiam (Favaro, 2017, p. 198).
}

Kuenzer (2007) recupera o debate dos autores franceses e infere que as típicas formas de organização do trabalho no modo taylorista/fordista, de natureza rígida, expressaram a dualidade estrutural com a definição das trajetórias educativas de acordo com as classes sociais, com o intuito de atender às necessidades de disciplinamento e formação de dirigentes e trabalhadores, com a fragmentação entre trabalho instrumental e intelectual. 
A partir dos fundamentos deste novo tipo de trabalho - a fragmentação, a separação entre trabalho instrumental e intelectual, a organização em linha e o foco na ocupação -, a dualidade estrutural, tal como foi sistematizada pelos clássicos do críticoreprodutivismo, expressou-se por meio da oferta de escolas que se diferenciavam segundo a classe social que se propunham a formar: trabalhadores ou burgueses (Kuenzer, 2007, p. 1155-1156).

No Brasil, ao longo do século XX, a autora explica que isso se viabilizou com a oferta de escolas profissionais e acadêmicas, revelando-se a dualidade especialmente no Ensino Médio. A educação profissional desenvolveu-se então de forma caótica, para atender o movimento do mercado, sem seguir uma política específica, em consonância com a expansão dos setores industriais, comerciais e de serviços, intensificada na década de 1940. Bastava uma formação profissional operacional, parcial, dispensando o trabalho intelectual e privilegiando o saber tácito, sem integrá-la com a educação geral. "A expansão da oferta de escolas profissionais, portanto, não resulta em democratização, mas sim em aprofundamento das diferenças de classe (Kuenzer, 2007, p. 1157).

Vigorava o projeto nacional-desenvolvimentista e a finalidade no Ensino Médio era preparar para o trabalho, expressando a distinção social existente mediada pela educação, segundo Ciavatta e Ramos (2011). A luta dos educadores pela educação pública na década de 1980 configurou-se então na defesa de uma educação unitária, omnilateral e politécnica, para a superação das desigualdades de classes, especialmente no âmbito educacional.

Com a aprovação da atual LDBEN, porém, foi destacada a formação "para a vida" substituindo a formação "para o trabalho", mediante um contexto de desregulamentação econômica e flexibilização social. Isso "[...] significaria desenvolver nas pessoas competências genéricas e flexíveis, de modo que elas pudessem se adaptar facilmente às incertezas de um mundo contemporâneo" (Ciavatta \& Ramos, 2011, p. 30).

Para as autoras, a "fragmentação curricular" e a "rotatividade formativa" demarcam a atual formação flexível, centrada na dualidade de classes e do sistema educacional brasileiro. Isso ocorre sob a defesa de que "[...] um currículo flexível supostamente proporcionaria ao trabalhador oportunidades de se atualizar ou se requalificar por diferentes itinerários formativos, demandados por mudanças na produção e/ou nas situações de emprego" (Ciavatta \& Ramos, 2011, p. 31).

Os efeitos da acumulação flexível na educação têm sido amplamente discutidos. Exigese novo disciplinamento das subjetividades, tanto para a produção como para a submissão à 
intensificação e à precarização do consumo da força de trabalho, demandando para a educação a tarefa de formar trabalhadores flexíveis. Para Kuenzer (2007, p. 1159), requer-se dos trabalhadores “[...] que acompanhem as mudanças tecnológicas decorrentes da dinamicidade da produção científico-tecnológica contemporânea, ao invés de profissionais rígidos, que repetem procedimentos memorizados ou recriados por meio da experiência”.

Para essa autora, a base flexível (toyotismo) daria as condições para a negação da dualidade estrutural, pois extingue a separação rígida no trabalho e demanda "domínio de competências cognitivas complexas". Assim sendo, “[...] a integração entre as trajetórias de escolaridade e laboral resultará na articulação entre teoria e prática, resgatando-se, desta forma, a unidade rompida pela clássica forma de divisão técnica do trabalho [...]” (Kuenzer, 2007, p. 1157). À primeira vista, as bases para a superação da dualidade estrutural estariam dadas, por meio das superestruturas, como a escola, que ofertaria um único percurso para todos na Educação Básica, viabilizando a democratização do acesso.

Diante da materialidade do real, Kuenzer (2007, 1165) pondera, entretanto, que a dualidade “[...] não se supera, mantendo-se e fortalecendo-se, a partir de uma outra lógica”. Isso porque, diferentemente do discurso de negação, a flexibilização aprofunda a dualidade estrutural por intensificar as desigualdades de classes, resultando em uma "inclusão excludente".

São combinações que ora incluem, ora excluem trabalhadores com diferentes qualificações, de modo a constituir corpos coletivos de trabalho dinâmicos, por meio de uma rede que integra diferentes formas de subcontratação e trabalho temporário, e que, ao combinar diferentes estratégias de extração de mais-valia, asseguram a realização da lógica mercantil (Kuenzer, 2017, p. 340).

Ela concebe que há um processo cíclico de inclusão (por políticas públicas) e de exclusão (não permanência no mercado de trabalho) na educação escolar, como forma de manutenção da lógica de acumulação flexível. Quanto à formação que é ofertada:

[...] importa menos a qualificação prévia do que a adaptabilidade, que inclui tanto as competências anteriormente desenvolvidas, cognitivas, práticas ou comportamentais, quanto a competência para aprender e para submeter-se ao novo, o que supõe subjetividades disciplinadas que lidem adequadamente com a dinamicidade, a instabilidade, a fluidez (Kuenzer, 2017, p. 341).

O resultado é que são necessárias distintas e variadas qualificações da força de trabalho, aprofundando a distribuição desigual do conhecimento, já que a maioria estará ocupada em trabalhos simples e desqualificados, sendo suficientes treinamentos rápidos e certificações de 
competências. No que tange à reforma do Ensino Médio, portanto, Kuenzer (2017, p. 341) infere que "[...] a organização curricular aprovada, ao flexibilizar os percursos, institucionaliza o acesso desigual e diferenciado ao conhecimento".

Essas discussões remetem à necessidade de considerar alguns aspectos estruturais que incidem sobre a educação e a totalidade social. O primeiro deles é que, em uma organização social dividida em classes, a desigualdade é inevitável, em todos os âmbitos, inclusive no interior da escola, que é marcada por variados percursos formativos. Além disso, todos encontram-se "incluídos" nessa lógica social, em uma de suas classes, sendo que o que determinada esse pertencimento é a posse ou não dos meios de produção, e não a formação escolar obtida.

Desconsiderar esses fundamentos estruturais pode remeter à busca de causas e soluções na esfera política, o que está em desacordo com o que se compreende da relação entre a educação e a base material neste estudo. Em contraposição a isso, problematizando essa via de solução para a dualidade escolar e pautando-se na análise da determinação econômica, Bertoldo (2018, p. 6) concebe que, “[...] se a dualidade tem seu fundamento aí, isto é, na esfera econômica, é apenas no âmbito dela que encontraremos a sua resolução".

Ademais, Tonet (2012) afirma que, com o surgimento da sociedade de classes, a educação passou a ser organizada em seus métodos e conteúdos com o intuito de atender aos interesses da classe dominante, sendo que a desigualdade social passou a ser encarada como algo natural. Ao se articular a educação com o processo histórico, destaca-se que o surgimento da propriedade privada e das classes sociais instaurou a exploração e a dominação do homem pelo próprio homem, o que certamente recai sobre todas as atividades da realidade social, que foram estruturadas para reproduzirem os interesses das classes dominantes.

Com a educação não podia ser diferente. Tanto na educação informal como na formal, se impõe a hegemonia das classes dominantes. O que não significa que a educação seja uma mera reprodutora dos interesses dessas classes, pois numa sociedade de classes, a educação, assim como todas as outras dimensões sociais, é sempre o resultado da luta entre as classes. Significa, apenas, que ela estará sempre sob a hegemonia das classes dominantes (Tonet, 2012, p. 54).

Para o autor, a forma de pensar a relação entre a formação humana e a educação, que parte do princípio da eterna busca de melhorias, fica entre o ideal e a realidade objetiva, se caracterizando como uma concepção idealista, pois, ao assumir como função da subjetividade 
estabelecer o ideal, a realidade objetiva consistiria em se configurar a partir de algo préestabelecido.

Para superar a dualidade estrutural, Kuenzer (2007, p. 1176) assevera que “[...] é exatamente esta realidade, mediante a estimulação do avanço na construção de práticas educativas, que forma subjetividades comprometidas com a transformação das relações sociais”. Dessa forma, a educação, “[...] na perspectiva da unilateralidade, por contradição, permite recuperar a concepção de omnilateralidade como um dos fundamentos dos processos de formação humana". Embora se considere legítimo esse objetivo, questiona-se se a efetiva concretização dessa formação humana e da própria subjetividade revolucionária, por intermédio de práticas educativas, não esbarra na determinação estrutural das relações de produção e do pertencimento do indivíduo a determinada classe social.

Kuenzer (2017, p. 342) concluiu, posteriormente, que os recentes processos de aprovação da Reforma do Ensino Médio, sem diálogo e sob resistências, “[...] atestam a força da base material na estruturação das políticas públicas na acumulação flexível’. Resta para ela o desafio de construir novos espaços formativos que desvelem a ideologia, para construir um projeto contra hegemônico que leve à emancipação dos trabalhadores, pois a escola tem sido invadida pela lógica mercantil e pela despolitização das práticas educativas.

Analisando a realidade atual do Ensino Médio brasileiro, entende-se que não se trata de uma "dualidade" que exclui os trabalhadores do Ensino Superior. O ingresso de todos nesse ensino é inclusive desejável para o capital, tendo em vista a mercantilização da educação como um todo (de algum modo, todas as atividades foram privatizadas). O Ensino Superior está inserido na lógica do mercado, por isso interessa ao capital ter um número crescente de pessoas adquirindo essa mercadoria, com ou sem qualidade.

Nesse sentido, cabe indicar que o domínio do capital sobre a educação não é algo recente, ela tem estado a seu serviço, mesmo sob resistências. Isso porque a sociedade burguesa e sua forma de trabalho (compra e venda da força de trabalho) conduzem à produção da desigualdade social e, na lógica capitalista, exige-se a exploração do trabalho. É nesse sentido que Mészáros (2008, p. 15) assevera que a educação, dentro do processo de acumulação de capital, se tornou parte da reprodução do sistema de classes, e "[...] mecanismo de perpetuação e reprodução desse sistema". 
A relação entre capital e trabalho sempre implicará na exploração do homem pelo homem. Diante disso, em uma sociedade de classes, a educação é organizada de modo a reproduzir os interesses das classes dominantes e, por isso, a essência desse entendimento revela, no que se refere à formação humana, que "[...] tanto o acesso universal quanto a qualidade não passam de uma falácia" (Tonet, 2012, p. 83). Torna-se "inútil” buscar a efetivação de uma educação que contribua para a formação integral, dentro dessa forma de sociabilidade. Uma nova educação só se dará concomitante à luta por uma nova sociedade.

É necessário, portanto, levar em conta o pressuposto de que a escola, como parte de uma prática social fragmentada, dividida em classes, também expressa e reproduz essa fragmentação, por meio de sua organização interna, seus conteúdos, métodos e formas de organização e gestão. Infelizmente, não é a aprovação legal de uma educação integral nem o desejo sincero de que isso se efetive que assegura a mudança na prática real das escolas, isso demanda outra lógica social.

A problemática derivada desses apontamentos e que exige estudos coletivos é a viabilidade de propor uma formação igualitária sob uma sociedade desigual. Além disso, supondo-se ser possível uma educação integral e de qualidade para todos sob o capital, restaria ainda a necessidade de apreender a relação entre trabalho e capital, verificando os reais determinantes da condição social, da formação e do trabalho nesta lógica social.

\section{Considerações finais}

A atual Reforma do Ensino Médio de 2017 foi amparada na considerada insuficiência do sistema escolar, o que justificaria medidas radicais e profundas, inclusive a parceria com o setor privado, avaliado como mais eficiente. Nesse processo, articulado à totalidade mais ampla, concebe-se que a educação compõe o mercado, tornando-se uma mercadoria lucrativa.

A formação educacional e as perspectivas profissionais dos jovens brasileiros sofrem assim os rebatimentos da lógica do capital, que mantem as desigualdades educacionais devido às influências do seu pertencimento a determinada classe social. Tais diferenciações tem gerado amplos debates e, na tradição de viés crítico, considerou-se que a escola é perpassada por uma dualidade e até que essa dualidade escolar aprofundaria a diferença social.

No que diz respeito à questão da desigualdade presente no sistema educacional e no Ensino Médio brasileiro, conclui-se nesta análise que ela é expressão da totalidade estrutural, 
que se dá nas relações materiais de produção da vida. Essa estrutura articula-se com a política, a ideologia e com a própria educação, em meio a embates, estabelecendo em última instância os parâmetros em que as mesmas se organizam para assegurar a reprodução do capital.

Infere-se, portanto, que não é possível considerar uma solução efetiva para a problemática da "dualidade escolar" (ou como se prefere denominar, a desigualdade presente no sistema educacional) dentro das relações capitalistas, pois esta se refere a uma desigualdade social estruturante, produto da organização social que tem como matriz a propriedade privada e a fragmentação de classes sociais. A exploração da força de trabalho e a intensificação da mercantilização do ensino em todos os níveis é que tem determinado as políticas implantadas, o que torna incoerente acreditar em uma formação integral inserida em um contexto de exploração, precarização e desemprego.

\section{Referências}

Altmann, H. (2002). Influências do Banco Mundial no projeto educacional brasileiro. Educação $e$ Pesquisa, 28 (1), 77-89. http://www.scielo.br/pdf/ep/v28n1/11656.pdf.

Bertoldo, E. (2018). A dualidade estrutural na reforma do ensino médio. Gesto Debate, 6 (1), 01-06. https://cdn-cms.f-static.net/uploads/1154357/normal_5afb241791732.pdf.

Borges, E. F., \& Araújo, J. C. S. (2019). Educação profissional, dualidade estrutural e neoprodutivismo. Revista Educação em Questão, $57 \quad$ (52), 1-33. https://periodicos.ufrn.br/educacaoemquestao/article/view/16002.

Brasil. (1996, 23 dezembro). Lei $n^{\circ}$ 9.394, de 20 de dezembro de 1996. Estabelece as Diretrizes e Bases da Educação Nacional. http://www.planalto.gov.br/ccivil_03/Leis/L9394.htm.

Brasil. (2017, 17 fevereiro). Lei $n^{o}$ 13.415/2017, de 16 de fevereiro de 2017. Altera as Lei $\mathrm{n}^{\circ}$ 9.394, de 20 de dezembro de 1996 e institui a Política de Fomento à Implementação de Escolas de Ensino Médio em Tempo Integral. Brasília, DF. http://www.planalto.gov.br/ccivil_03/_ato2015-2018/2017/lei/L13415.htm.

Ciavatta, M., \& Ramos, M. (2011). Ensino Médio e Educação Profissional no Brasil: Dualidade e fragmentação. Revista Retratos da Escola, $5 \quad$ (8), 27-41. http://retratosdaescola.emnuvens.com.br/rde/article/view/45/42.

Costa, M. A., \& Coutinho, E. H. L. (2018). Educação Profissional e a Reforma do Ensino Médio: Lei $\mathrm{n}^{\mathrm{o}}$ 13.415/2017. Educ. Real., 43 (4), 1633-1652. http://www.scielo.br/scielo.php?script=sci_arttext\&pid=S217562362018000401633\&lng=pt\&nrm=iso.

Favaro, N. (2017). Pedagogia histórico-crítica e sua estratégia política: fundamentos e limites. 2. ed. Maceió: Coletivo Veredas. 
Ferretti, C. J. (2018). A reforma do Ensino Médio e sua questionável concepção de qualidade da $\begin{array}{lllll}\text { educação. } & \text { Estudos } & \text { Avançados, } & 32 & \text { (93), }\end{array}$ https://www.scielo.br/scielo.php?script=sci_arttext\&pid=S0103-40142018000200025.

Frigotto, G., \& Ciavatta, M. (2003). Educação básica no Brasil na década de 1990: subordinação ativa e consentida à lógica do mercado. Educ. Soc., 24 (82), 93130. https://doi.org/10.1590/S0101-73302003000100005.

Harvey, D. (2008). O neoliberalismo: história e implicações. São Paulo: Loyola.

Kuenzer, A. Z. (2007). Da dualidade assumida à dualidade negada: o discurso da flexibilização justifica a inclusão excludente. Educ. Soc., 28 (100), 1153-1178. https://www.scielo.br/scielo.php?pid=S0101$\underline{73302007000300024 \& \text { script=sci_abstract\&tlng=pt. }}$

Kuenzer, A. Z. (2017). Trabalho e escola: a flexibilização do ensino médio no contexto do regime de acumulação flexível. Educ. Soc., 38 (139), 331-354. https://doi.org/10.1590/es0101$\underline{73302017177723 .}$.

Leher, R. (2005). Educação no Governo Lula da Silva: Reformas sem Projeto. Adusp.

Marx, K., \& Engels, F. (2005). Manifesto comunista. São Paulo: Boitempo.

Mészáros, I. (2008). A educação para além do capital. 2. ed. 2008. São Paulo: Boitempo.

Netto, J. P., \& Braz, M. (2006). Economia Política: uma introdução crítica. São Paulo: Cortez.

Neves, L. M. W., \& Pronko, M. A. (2008). O mercado do conhecimento e o conhecimento para o mercado: da formação para o trabalho complexo no Brasil. Rio de Janeiro: EPSJV.

Santos, D. (2017). Educação e precarização profissionalizante: crítica à integração da escola com o mercado. São Paulo: Instituto Lukács.

Soares, M. C. C. (2000). Banco Mundial: políticas e Reformas. In: Tommasi, L., Warde, M. J., \& Haddad, S. (Orgs.). O Banco Mundial e as políticas educacionais, (15-40). São Paulo: Cortez.

Tonet, I. (2012). Educação contra o capital. São Paulo: Instituto Lukács.

Tumolo, L. M. S., \& Tumolo, P. S. (2019). A vivência do desempregado: um estudo crítico do significado do desemprego no capitalismo. In: Tumolo, P. S. (Org.). Trabalho, capital e formação da classe trabalhadora, (123-146). Florianópolis: Editoria Em Debate, UFSC.

Zibas, D. M. L. (2005). A reforma do ensino médio nos anos de 1990: o parto da montanha e as novas perspectivas. Rev. Bras. Educ., (28), 24-36. http://www.scielo.br/pdf/rbedu/n28/a03n28.pdf.

\section{Autores}

Caroline de Lima Mendonça

Estudante de Graduação em Pedagogia e Pesquisadora do Programa de Iniciação Científica na Universidade Estadual do Paraná (UNESPAR), Campus Paranavaí. Participante do Grupo de Estudos e Pesquisas Trabalho e Educação da Sociabilidade e Capital (GEPTESC): http://dgp.cnpq.br/dgp/espelhogrupo/271903. Lattes: http://lattes.cnpq.br/8840261601834890 . ORCID: https://orcid.org/0000-0002-3326-4649. E-mail: carol.lima.mendonca@ hotmail.com . 
Neide de Almeida Lança Galvão Favaro Doutora em Educação (UFSC). Professora do Colegiado de Pedagogia e do Programa de PósGraduação em Ensino: Formação Docente Interdisciplinar (PPIFOR), na Universidade Estadual do Paraná (UNESPAR), Campus Paranavaí. Líder do Grupo de Estudos e Pesquisas Trabalho e Educação da Sociabilidade e Capital (GEPTESC): http://dgp.cnpq.br/dgp/espelhogrupo/271903. Pesquisadora do Grupo de Estudos Capital, Trabalho e Educação (GECATE): http://dgp.cnpq.br/dgp/espelhogrupo/52985. Lattes: http://lattes.cnpq.br/6325209425358903. ORCID: https://orcid.org/0000-0003-0569-7225.

E-mail: neidegafa@hotmail.com

Priscila Semzezem Mestre em Serviço Social e Política Social (UEL). Doutoranda em Serviço Social (UFSC). Professora do Colegiado de Serviço Social da Universidade Estadual do Paraná (UNESPAR),

Campus Paranavaí. Vice-Líder do Grupo de Estudos e Pesquisas Trabalho e Educação na Sociabilidade do Capital (GEPTESC): http://dgp.cnpq.br/dgp/espelhogrupo/271903. Lattes: http://lattes.cnpq.br/1012388941501759. ORCID: https://orcid.org/0000-0002-5410-2585.

E-mail: priscilasemzezem@ hotmail.com.

Rita de Cássia Pizoli

Doutora em Educação (UEM). Professora do Colegiado de Pedagogia na Universidade Estadual do Paraná (UNESPAR), Campus Paranavaí. Pesquisadora do Grupo de Estudos e Pesquisas Trabalho e Educação da Sociabilidade e Capital (GEPTESC):

http://dgp.cnpq.br/dgp/espelhogrupo/271903. Lattes: http://lattes.cnpq.br/8835078921002360 ORCID: https://orcid.org/0000-0003-0127-3679 . E-mail: ritacpizoli@ hotmail.com.

\section{Como citar o artigo}

MENDONÇA, C. L.; FAVARO, N. A. L. G.; SEMZEZEM, P.; PIZOLI, R. C. O Ensino Médio brasileiro e a questão da dualidade escolar. Revista Paradigma Vol. XLII, Nro. 2, Diciembre de $2021 / 397-415$.

DOI: https://doi.org/10.37618/PARADIGMA.1011-2251.2021.p397-415.id974 